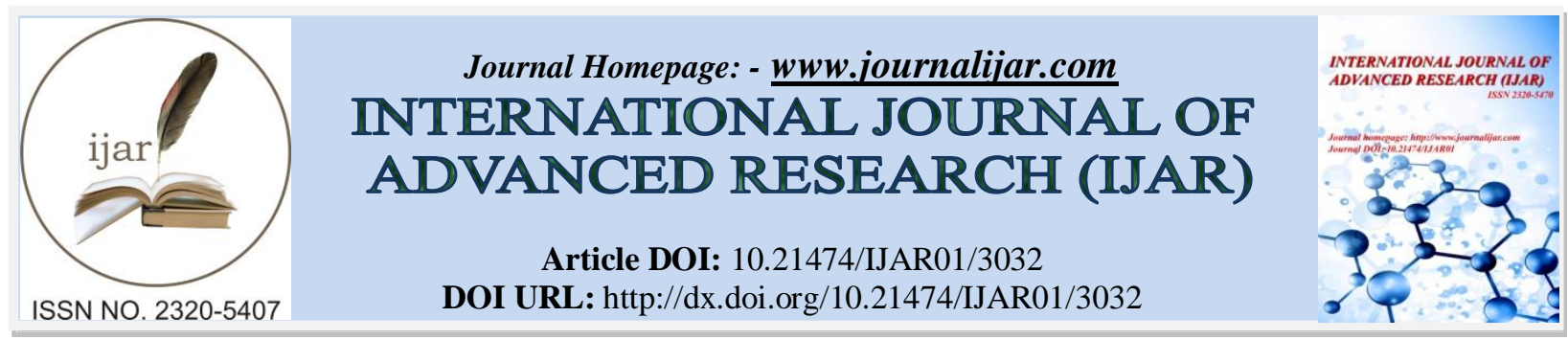

RESEARCH ARTICLE

\title{
MATERNAL PARENTING STYLE AND CHILDREN'S ELECTRONIC USE AMONG UNIVERSITY FEMALE EMPLOYEES, SAUDI ARABIA.
}

Eman M. mortada ${ }^{1}$, Ayah A. Aloubal ${ }^{2}$, Amira A. Almohishir ${ }^{2}$ and Malak F. Almehaijeen ${ }^{2}$.

1. $\mathrm{PhD}$ in public health and preventive medicine, Assistant Professor in health sciences department, Health and rehabilitation sciences college, Princess Noura Bint Abdelrhaman University.

2. Graduate students, epidemiology program, health sciences department, Health and rehabilitation sciences college, Princess Noura Bint Abdelrhaman University.

\section{Manuscript Info}

(.........................

Manuscript History

Received: 30 November 2016

Final Accepted: 28 December 2016

Published: January 2017

Key words:-

Parenting style, Screen time,

Restrictions, health hazards, Children.

\section{Abstract}

Background: Technology is becoming an essential part of life, especially for children born and growing up with it. Therefore, it is important to know how it is affecting them socially, physically and behaviorally. Different parents have different attitudes and behaviors that determine how they deal with their children, the variety of parenting styles can have different outcomes on the children's use of electronics.

Objectives: Firstly, to identify different parenting style among mother employees at Princess Nora University, then determine the effect of different parenting styles on the hours spent by children on electronic devices and lastly, assess the level of perceived potential negative hazards of electronics.

Methods: A cross-sectional study has been conducted, with a standard, multi-sectional modified questionnaire. Sample size was 280 females obtained by multistage stratified sampling.

Results: The most common parenting style was the Authoritative. Screen time use was positively correlated with permissive parenting style (.09), and was negatively correlated with the authoritarian and authoritative parenting style (-.01). The majority of mothers perceived that the use of electronics has a mild impact on their children's physical health. Overall, there is a significant relationship between permissive parenting style and setting restrictions on electronics use ( $p=0.04)$, and significant effect on children's time spent on electronics per week $(p=.057)$.

Conclusion: Findings showed no significance between parenting style and children's screen time use. However, children's health was affected, therefore, parents must apply restrictions on screen-time use.

Copy Right, IJAR, 2016,. All rights reserved.

\section{Introduction:-}

In recent modern days, parenting styles have changed according to the technological evolution. Every parent has a different approach to the uprising technological use depending on their parenting style which can be explained as 
"parenting style as a typology of attitudes and behaviors that characterize how a parent will interact with a child across domains of parenting" (1), and other authors defined it as "Complex activity that includes many specific behaviors that work individually and together to influence child's outcomes. The construct of parenting style is used to capture normal variation in parents' attempts to control and socialize their children". As a result of the sudden invasion of technology and its increasing usage among children as they grow older "Children's screen time increases with age and patterns of screen time appear to be stable over time" (2), and some studies suggested that communication and parenting style predicted disagreements between parents and children about technological devices and internet usage ${ }^{(3)}$.

Parenting style includes four basic patterns that were identified by Baumrind: The Authoritarian parents who are known to be obedience- and status-oriented are characterized by high standardized guidelines and demands, tend to be direct with their instructions and are unresponsive. Due to fear of losing control, they discourage open communication, provide ordinal and structural rules, which are expected to be obeyed by their children without any explanation. Authoritarian-Directive parenting can have two forms of styles: Authoritarian parents who are not intrusive or autocratic in their use of power, and authoritarian parents who are highly intrusive. The Authoritative parents who use supportive disciplinary methods are characterized by moderate demands, acceptance and responsiveness as well as open communication. They are assertive and restrictive rather than intrusive, thus setting clear rules and guideline for their children and tend to encourage their children to be autonomic, assertive and socially responsible as well as cooperative. The Permissive parents who are also known as (Indulgent) or (Nondirective) are characterized by high acceptance and responsiveness, and non-demanding. These parents lack control over their children and avoid confrontation. They are also known to be lenient, non-traditional, do not require mature behaviors and allow self-autonomy by giving their children the freedom to be independent .In some cases, some parents tend to be democratic permissive parents who are more conscientious, engaged and committed to their child unlike the non-directive permissive parents who are known to be less engaged and committed to their children. The Uninvolved parents who might encompass both rejecting-neglecting attitudes are characterized by unresponsiveness nor demanding, fail to monitor and supervise the child's behavior and are uninvolved in with their children's hobbies and activities. ${ }^{(4)}$

The Saudi community has shown an increased interest in technology in the past years, especially children and teenagers who are early adopters and heavy users of technology, who are referred to as digital natives and whose electronic devices are becoming an essential part of their daily lives, whether it's for an educational or entertainment purposes $^{(5)}$. This huge technology revolution alerted parents who are digital immigrants, about the impact of electronic devices on their children ${ }^{(5)}$ and alerted them about several technological hazards which included intensive usage for technological devices, increased aggressive thoughts, angry feelings, physiological arousal, aggressive behaviors, and physiological desensitization to violence due to violent video game exposure ${ }^{(6)}$, and obesity, which is another hazard for technology use due to its bi-relationship with the amount of hours spent on devices like TV, computer and IPad, which means the more time spent on technology, the chance of becoming an obese increases. ${ }^{(7)}$ A study conducted on parenting Style, the Home Environment, and Screen Time concluded that "The global increase in prevalence of childhood overweight and obesity has been ascribed to several trends including the increase in consumption of energy-dense diets and the increase in sedentary behavior (in particular the increase in screen time; time spent watching TV and on computers or game consoles)". ${ }^{(8)}$

A great number of studies regarding parental control were conducted and concentrated on the impact of technology consumption on children's physical activity and sedentary lifestyle "Parents with greater support for physical activity did not report higher use for parenting practices that restricted child's screen media use. Greater reported use of restrictive TV parenting practices were associated with lower level of child PA". ${ }^{(4)}$ In contrast, there have been a number of researches conducted to study the benefits of technological devices use among children. In one study it was concluded that video games contributes to consolidates the cognitive skills by prompting reactions, improved alertness, attention and reinforces the mental abilities of children in addition to the satisfaction of emotional needs actively. ${ }^{(9)(10)}$

Level of autonomy available is affected by the number of children in a household and determined by the parents rules "family rules on watching TV are associated with less TV viewing and that high child autonomy is associated with more TV viewing". (11)(5) 
A previous study have highlighted that the amount of parent's knowledge about technology influences their control over their child's use of it. It was aforesaid that in many cases, parents who have enough knowledge about technology tend to check their children's browsing history and 30\% of parents in the UK and US remain physically present to censor their children's internet use and go to the extent of blocking what they perceive as unsuitable. ${ }^{(5)}$ In other words, parents have a great influence on their children's screen time. ${ }^{(2)}$ Although parenting style was assessed in relation to different domains like (child's physical activity, dietary habits, and as mentioned previously, internet censorship). "Parental use of reinforcement styles for activity was positively related to children's physical activity. Parents' use of appropriate disciplinary styles was positively related to children's healthy eating" (12) and technology use on the side effects of the child's health and cognitive intelligence has been assessed in previous studies, yet gaps exist in assessing the association between the parenting style and the time spent on technology use. To fill this gap, we decided to conduct a study to assess the parenting style in relation to children's electronic use and try to identify the determinants of children's use of electronics especially the parenting style to see if a future intervention is needed.

\section{Research question:-}

Is there an association between different parenting style and children electronic use and screen time exposure?

\section{Hypothesis:-}

The screen time use is affected by the different parenting style.

\section{Objectives:-}

To identify different parenting style among mother employees at PNU. Then, to determine the effect of different parenting styles on the screen time and the hours spent by children on electronic devices use, and to assess the level of perceived potential negative hazards of electronics use, they observe in their children.

\section{Methodology:-}

Study design and setting:-

A cross-sectional study conducted from April 2016 to December 2016 at PNU.

\section{Target population:-}

PNU female employees in Riyadh, Saudi Arabia whom have preschool and school children, whether administrative and teaching employees, since mothers, not only spend a lot more time with children than fathers, but also has more opportunities than the father to influence her offspring's psychological growth and behavior.

\section{Sampling techniqueand sample size:-}

A multi-stage stratified random sample was done on the 13 colleges in PNU, which were categorized under three main types, which are Health Colleges, Science Colleges and humanities colleges. From them, we randomly selected the college of Art and Design, Computer and Information Sciences, Health and Rehabilitation Sciences, Business Administration, Arts and Sciences. Then total sample size of 297, was calculated by using open epi ${ }^{(14)}$ adopting the following parameters: $80 \%$ power of the study to detect a statistical significant difference, $95 \%$ confidence interval and $34 \%$ of the members interviewed in the pilot study, reported that their children's exposure to electronic screens was less than 2 hours. The sample was stratified according to the number of administrative and teaching staff in each of the previously randomly chosen college.

\section{Tools for data collection:-}

A standard multi-section modified questionnaire has been translated and used to collect data and it includes several parts and guided by the conceptual framework illustrated in figure 1:

The first part covers the family characteristics (Mother, father and children) and home-physical environment. ${ }^{(5)}$ The second part includes questions about the use of electronic devices, which will include as the mothers were asked about the average time their child spent during recreational electronic use daily and during the weekend. In our study, we used 2 hours per day as the cut-off according to the international recommendations ${ }^{(14,15)}$ in addition to asking the mothers about the frequency with which they set limits on the time of recreational electronics use. The third part of the questionnaire assesses the level of perceived potential negative hazards of electronics use, they observe on their children in different domains: physical health (9 items), social relationships (3 items), behavioral changes ( 2 items), and educational performance ( 2 items) with four point responses (None, Mild, Moderate and 
Severe). ${ }^{(16)}$ The last part is derived from the modified 21-item Parenting Styles and Dimensions Questionnaire (PSDQ) designed to categorize mothers' parenting style based on various behaviors displayed by parents towards their children. This scale has three dimensions that are authoritative parenting style includes ( 9 items), authoritarian parenting styles includes ( 6 items), and permissive parenting style includes ( 6 items). The response to each item is measured on a 5-point Likert scale, 1="never", 2="once in a while", 3="about half of the time", 4="very often", $5=$ "always". ${ }^{(17)}$

\section{Questionnaire translation process and validation:-}

The questionnaire was translated into Arabic using forwards-backwards blind translation process by two bilingual expert translators, whose native language is Arabic and comparison (between the original English version and the back translation version) was done to measure the level Of agreement between both.

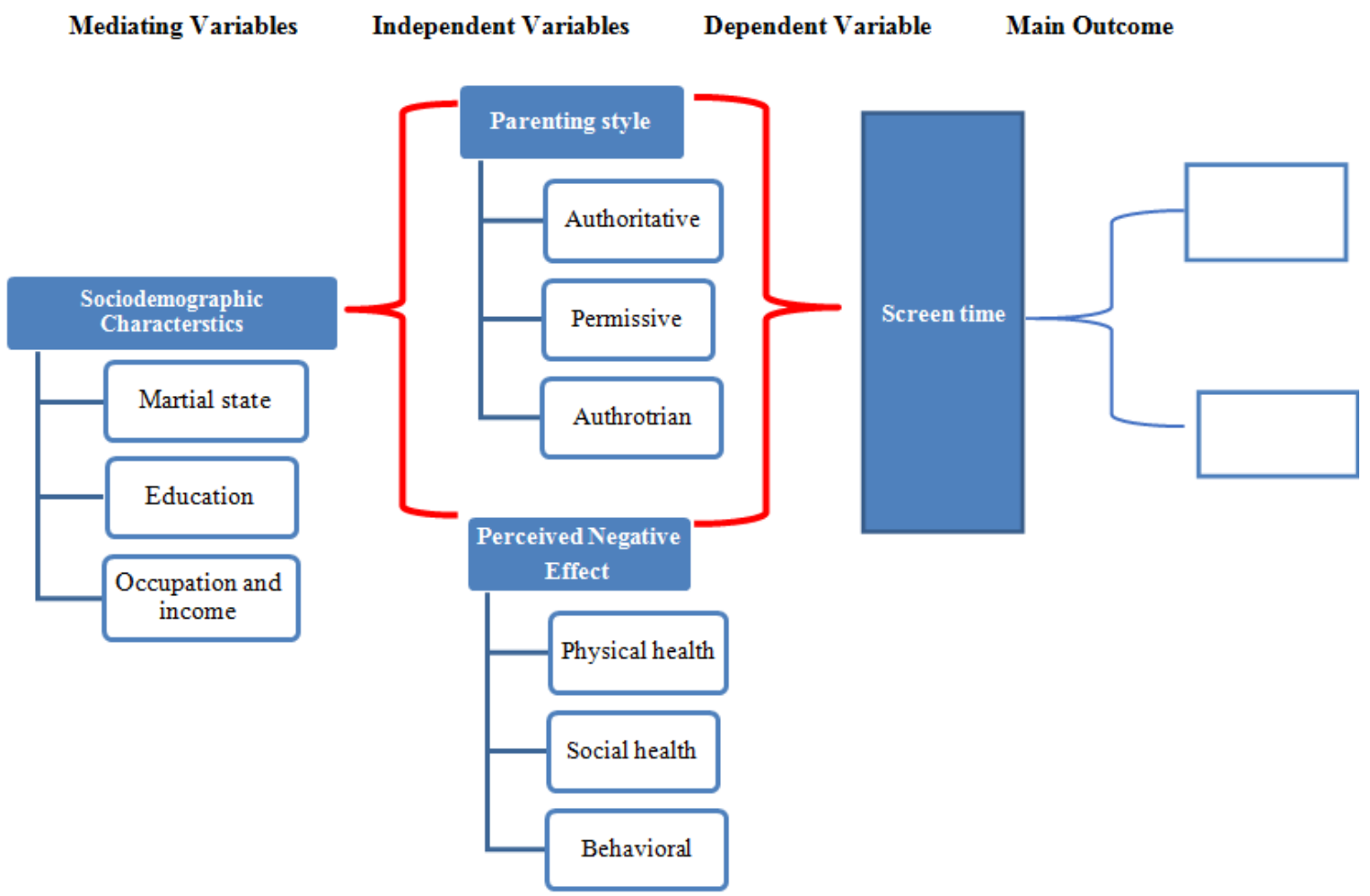

Figure 1:- Conceptual framework of factors used in the study

\section{Pilot testing:-}

The Arabic version of the tools has been pilot tested on 20 females in college of Nursing to assure comprehension and ease of administration, determining the time needed to fill the questionnaire in addition to calculating sample size based on the findings from the pilot study. According to the pilot test results, we made the necessary adjustments on the questionnaire. For example, we changed some of the open ended questions to close ended questions like age and nationally because a great number of participants left it blank.

\section{Data management and Statistical analysis:-}

After collecting data, it was analyzed by SPSS $20^{\text {th }}$ version ${ }^{(18)}$. Checking the normality for the quantitative variables was performed using the Kolmogorov test, all variables were normally distributed except for the Authoritative subscale. Then the data were described by frequency and percentage for categorical data, mean and standard deviation for normally distributed continuous variable and median and IQR for the authoritative. Inferential analysis was performed using Independent T-test, One-Way ANOVA and for continuous normally distributed variables while Mann- Whitney and Kruskal-Wallis tests for continuous not normally distributed variables. Chi sq uare to assess the association between recreational screen time use and educational achievement and social change. Spearman correlation coefficient to determine direction and strength of the relationship between different parenting style subscales and screen time use of their children on screen time. The reliability of the total parenting scale and its 3 subscales was assessed by using Cronbach alpha coefficient. 


\section{Ethical considerations:-}

Before collecting data, an approval has been taken from the ethics committee and research center in health sciences and rehabilitation collage, PNU. Consent from the participant after being informed about the purpose of the study, the confidentiality of the shared information and anonymity of the participants.

\section{Results:-}

Table 1:- Personal Characteristics of mother employee working at princess Nora Bint Abdulrhman University $(\mathrm{n}=280)$

\begin{tabular}{|c|c|c|c|}
\hline Personal characteristics & Categories & Frequency & Percentage \\
\hline Age groups & $25-35$ & 137 & 48.9 \\
\hline (years) & $36-45$ & 117 & 41.8 \\
\hline & More than 46 & 26 & 9.3 \\
\hline Nationality & Saudi & 239 & 85.4 \\
\hline Colleges & Non-Saudi & 41 & 14.6 \\
\hline & Art and Designs & 63 & 22.5 \\
\hline & Computer and Information Science & 42 & 15.0 \\
\hline & Health and Rehabilitation Science & 54 & 19.3 \\
\hline & Business Administration & 43 & 15.4 \\
\hline & Arts & 41 & 14.6 \\
\hline & Science & 37 & 13.2 \\
\hline Educational Level & High School & 43 & 15.4 \\
\hline & Bachelor & 140 & 50.0 \\
\hline & Master & 41 & 14.6 \\
\hline & PhD & 56 & 20.0 \\
\hline & Educational & 64 & 22.9 \\
\hline Work Nature & Administrative & 184 & 65.7 \\
\hline & Both & 32 & 11.4 \\
\hline Marital Status & Married & 261 & 93.2 \\
\hline & Divorced & 13 & 4.6 \\
\hline Number of children & Widowed & 6 & 2.1 \\
\cline { 2 - 4 } & $1-2$ & 125 & 44.6 \\
\cline { 2 - 4 } & $3-4$ & 112 & 40.0 \\
\cline { 2 - 4 } & More than 5 & 15.4 \\
\hline
\end{tabular}

Personal characteristics of the 280 mothers participated displayed in (Table 1). (48.9\%) are aged between 25 to 35 . $(85 \%)$ were Saudi and (50.0\%) of the participants hold a bachelor degree. (65.7\%) of participants were administrative employee, (93.2\%) were married, and the high proportion of them has 1-2 child (44.6\%)

Table 2:- 0 Mean scores and the reliability scale for total parenting scale and subscales.

\begin{tabular}{|l|c|c|c|c|c|}
\hline Parenting style & Minimum scores & Maximum scores & $\begin{array}{c}\text { Number of } \\
\text { items }\end{array}$ & $\mathbf{M} \pm$ SD & Cronbach alpha \\
\hline Authoritarian & 6.0 & 30.0 & 6.0 & $17.97 \pm 5.60$ & .80 \\
\hline Permissive & 6.0 & 26.0 & 6.0 & $16.48 \pm 4.01$ & .79 \\
\hline Authoritative* & 9.0 & 45.0 & 9.0 & $32.15 \pm 8.66$ & .88 \\
& & & & $\begin{array}{c}\text { Median=34, } \\
\text { IQR }=29-39\end{array}$ & \\
\hline Total parenting scale & 25.0 & 89.0 & 21.0 & $65.96 \pm 9.46$ & .72 \\
\hline
\end{tabular}

* Not normally distributed

As shown in (Table 2), after calculating the mean score for the 3 parenting subscales and assessing their normality, we found that the average for the mean score of authoritarian subscale was $(\mathrm{M}=17.97, \mathrm{SD}=5.7)$, the mean score of permissive subscale was $(\mathrm{M}=16.48, \mathrm{SD}=4.01)$. Regarding the authoritative subscale the median was 34 and IQR was (29-39), and after assessing the reliability of three parenting subscales, wassatisfactory the Cronbach alpha coefficient were $(\alpha=.80, .79$ and .88$)$ forauthoritarian subscale, the permissive subscale and the authoritarian respectively. 


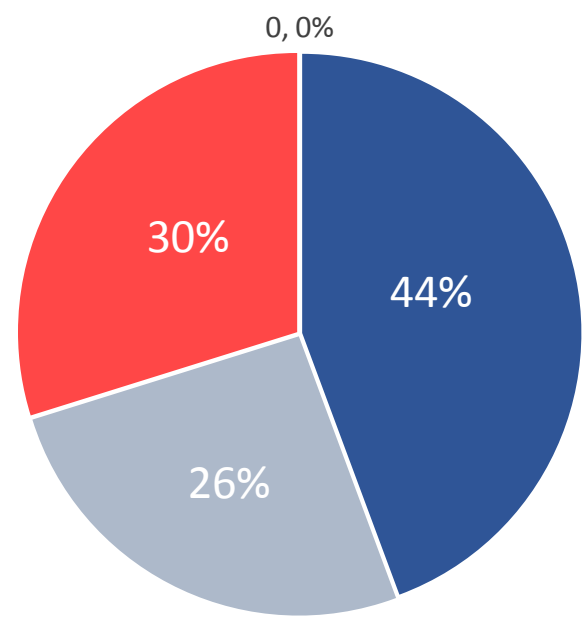

Authoritative

Permissive

Authoritarian

Figure 2:- Different types of parenting style among PNU female employees.

According to the findings shown in figure 2, 44\% of the participant mothers were adopting authoritative parenting style, $30 \%$ were authoritarian, while the rest $26 \%$ of participant were permissive

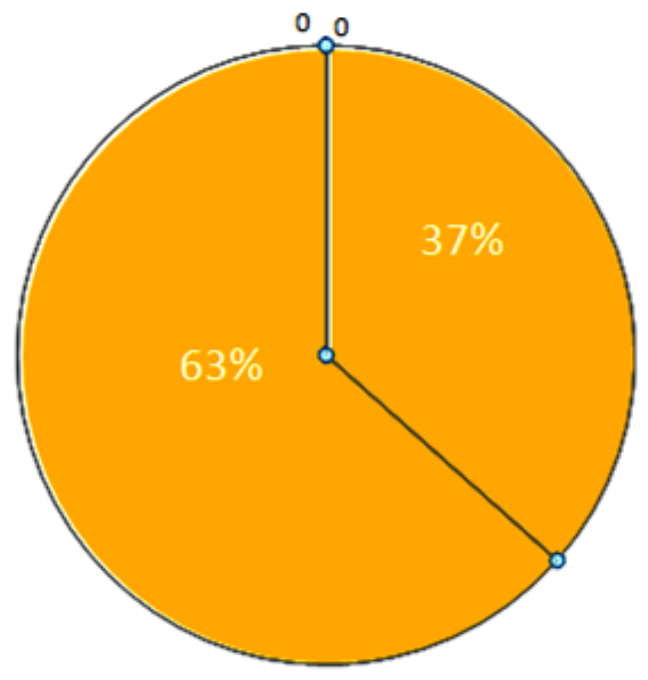

- Less Than Two Hours

- Equal or more Than Two Hours

Figure 3:- Percentage of Screen Time Use by PNU Employee's children on Electronics Devices The majority of sampled mothers (63\%)stated that their children spent more than two hours on their electronic devices (Figure 3).

Table 3:- Relationship Between Parenting Style, Perceived Negative Effect and Recreational Screen Time Use by The Children

\begin{tabular}{|c|c|c|c|c|}
\hline & \multicolumn{2}{|c|}{ Recreational Screen Time } & \multirow[t]{2}{*}{ Test used } & \multirow[t]{2}{*}{ P value } \\
\hline & $<2 \mathrm{~h}$ & $\geq 2 \mathrm{~h}$ & & \\
\hline Variables & $(n=103)$ & $(n=177)$ & & \\
\hline \multicolumn{5}{|c|}{ Parenting Style } \\
\hline \multicolumn{5}{|c|}{ Authoritative ** } \\
\hline $\mathrm{M} \pm \mathrm{SD}$ & $31.98 \pm 9.03$ & $32.24 \pm 8.45$ & -.22 & .83 \\
\hline \multicolumn{5}{|c|}{ Authoritarian } \\
\hline M \pm SD & $18.10 \pm 6.04$ & $17.90 \pm 5.41$ & .27 & .78 \\
\hline
\end{tabular}




\begin{tabular}{|l|c|c|c|c|}
\hline Permissive & & & \\
\hline M \pm SD & $15.94 \pm 4.08$ & $16.80 \pm 3.93$ & -1.65 & .09 \\
\hline Perceived negative effect & & & & \\
\hline Physical health problems & $3.65 \pm 3.99$ & $6.75 \pm 5.16$ & -5.26 & $.00 *$ \\
\hline M \pm SD & & & & $.04 *$ \\
\hline Behavioral health problems & $1.08 \pm 1.12$ & $1.38 \pm 1.21$ & -2.03 & .04 \\
\hline M \pm SD
\end{tabular}

*Significant difference at $\mathrm{p} \leq .05$

** Mann Whitney

As displayed, there was no significant effect found for the three parenting style subscales on recreational screen time. Nevertheless, a significant difference was found between perceived negative effect and recreational screen time. There was a significant difference between mothers perception of both physical health problems and behavioral health problems and the recreational screen time they allow for their children, $p$ (.00 and.04). (Table 3).

Table 4:- The Difference between Sociodemographic factors and screen time use

\begin{tabular}{|l|l|c|c|c|c|c|}
\hline \multicolumn{1}{|c|}{$\begin{array}{c}\text { Sociodemographic } \\
\text { factors }\end{array}$} & \multicolumn{1}{|c|}{ Categories } & \multicolumn{2}{c|}{ Recreational Screen } & Total & Chi & P \\
value
\end{tabular}

* Significant difference at $\mathrm{p} \leq .05$

As revealed, age of mothers was significantly related to the hours spent by children on electronics $(\chi 2(2)=8.33, p=$ 0.02). Younger Mothers aged from 25 to 35 (48.9\%) are more likely to apply restrictions on time spent by their children on electronic devices than mothers aged from 36 to 45 (41.8\%) and from 46 and more (9.3\%). On the other hand, there wasa significant relationship between the nationality of the mother and screen time use by the child $(\chi 2$ $(2)=6,163, p=0.01)$. (Table 4). 


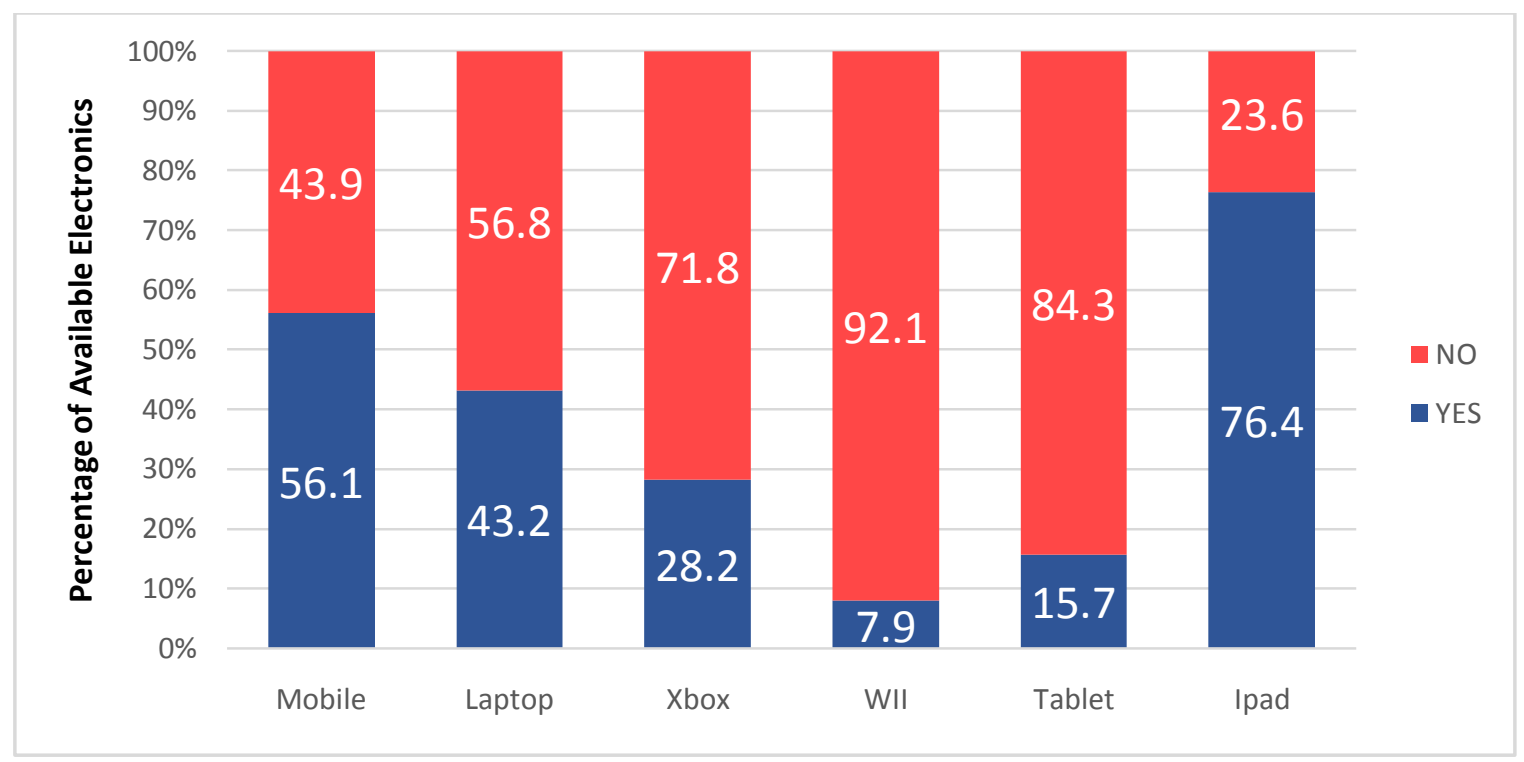

Figure 4:- Available Electronic devices for children in home

The most frequently available electronics for the children as stated by the mother were, iPad (76.4\%), mobile $(56.1 \%)$ and laptops $(43.2 \%)$ (Figure 4$)$.

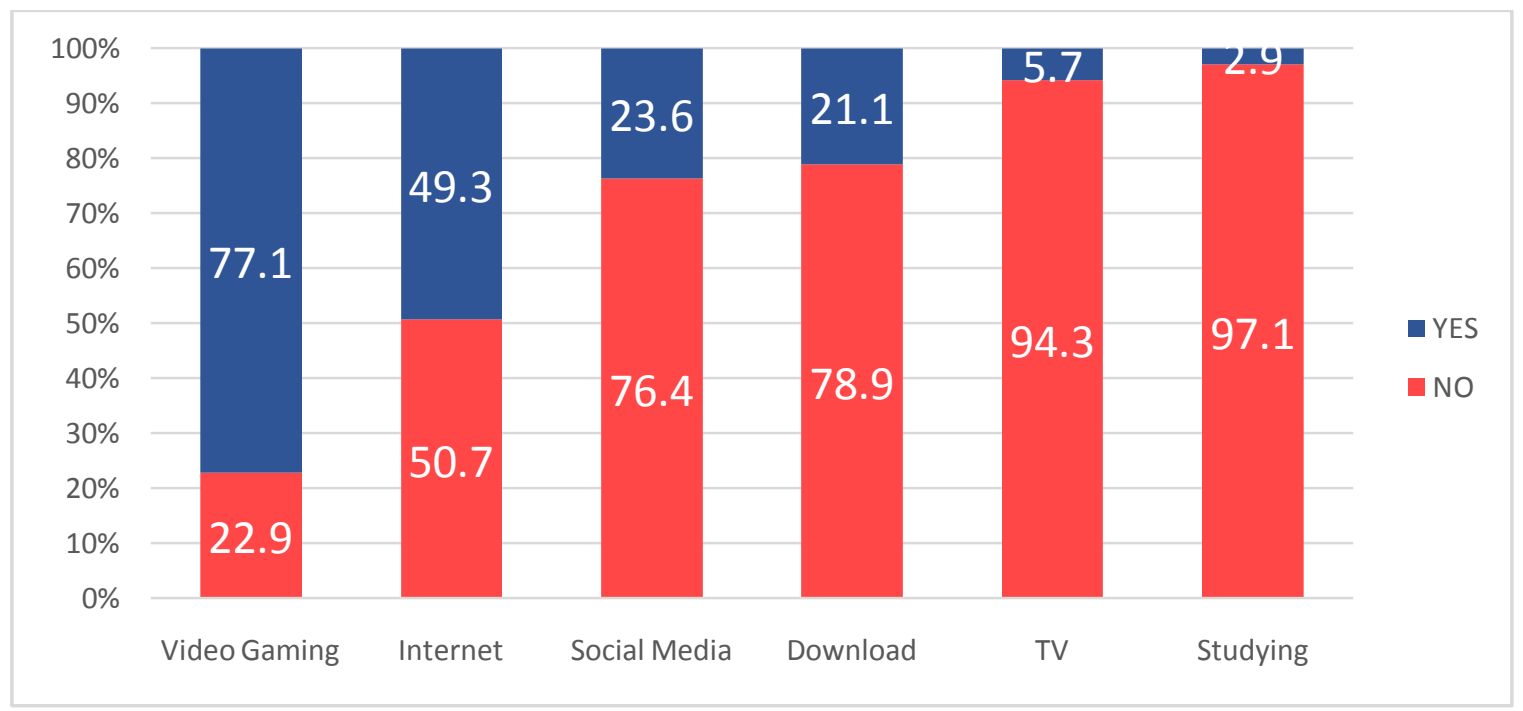

Figure 5:- Practiced activities by the child on electronic devices

Accordingto the mother's responses, the child's most practiced activities on electronic devices were video gaming (77.1\%), internet surfing (49.3\%) and activities on social media (23.6\%) (Figure 5). 


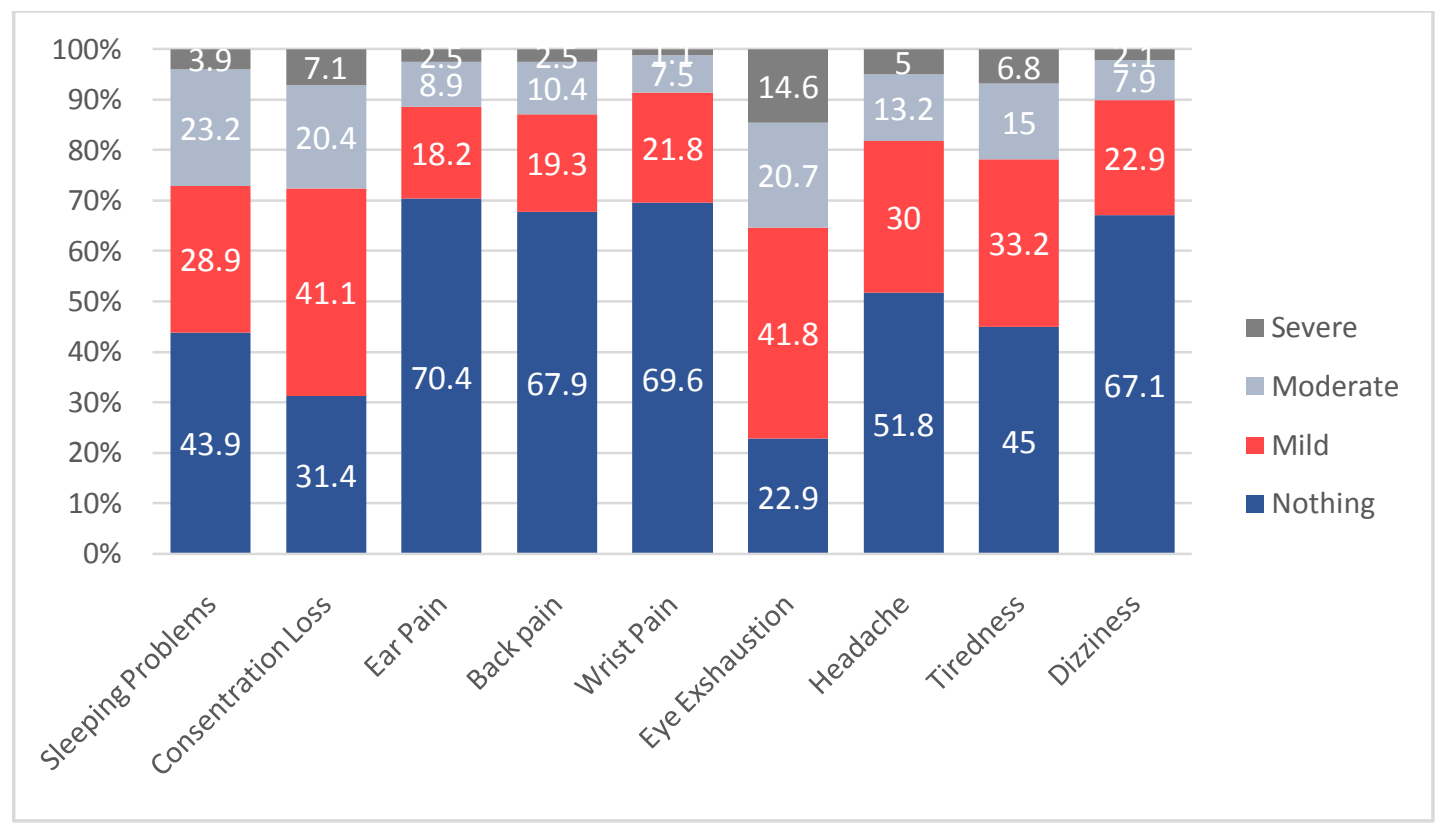

Figure 6:- Children with physical health problems as observed by their mothers due to Electronics use

The majority of the mothers perceived that the use of electronics have mild impact on their children physical health especially eye exhaustion, concentration loss, tiredness, headache and sleeping problems $(41.8 \%, 41.1 \%, 33.2 \%$, $30 \%$ and $28.9 \%$ ) respectively as displayed in (figure 6).

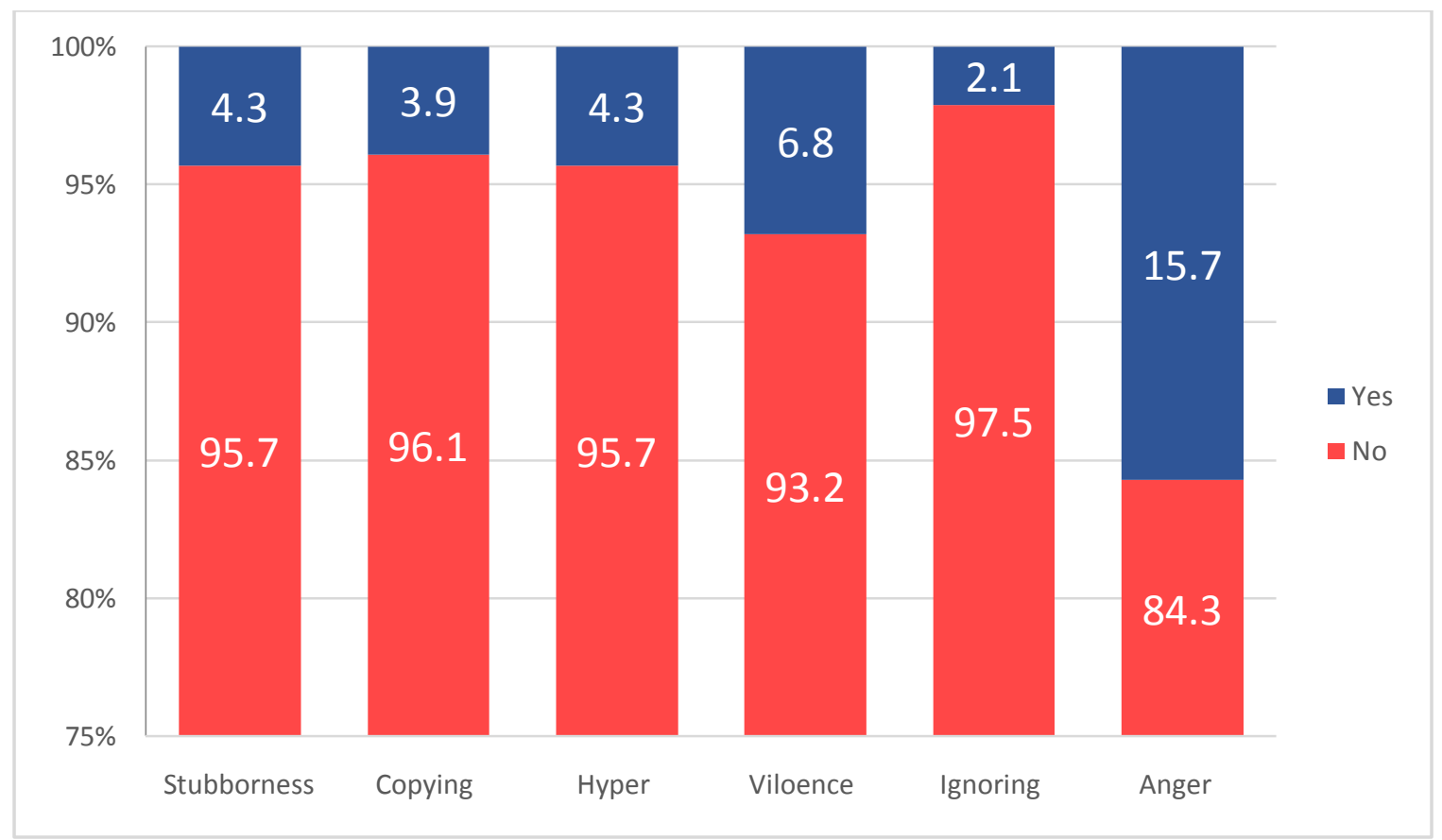

Figure 7:- Children's behavioral health problems observed by parents

The most frequent behavioral changes the mothers observed on their children after using electronic devices were stubbornness, anger, hyperactive, violence, ignoring $(4.3 \%, 15.7 \%, 4.3 \%, 6.8 \%, 2.1 \%)$ (Figure 7). 


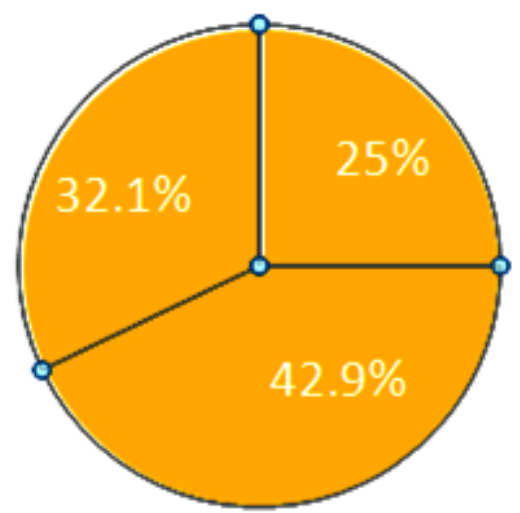

- Better

- Worse

- No effect

Figure 8:- Educational performance changes of children due to electronics use observed by mothers

The most observed change on the children's educational performance after using electronic devices as stated by the mothers was to the worse (42.9\%) (Figure 8 ).

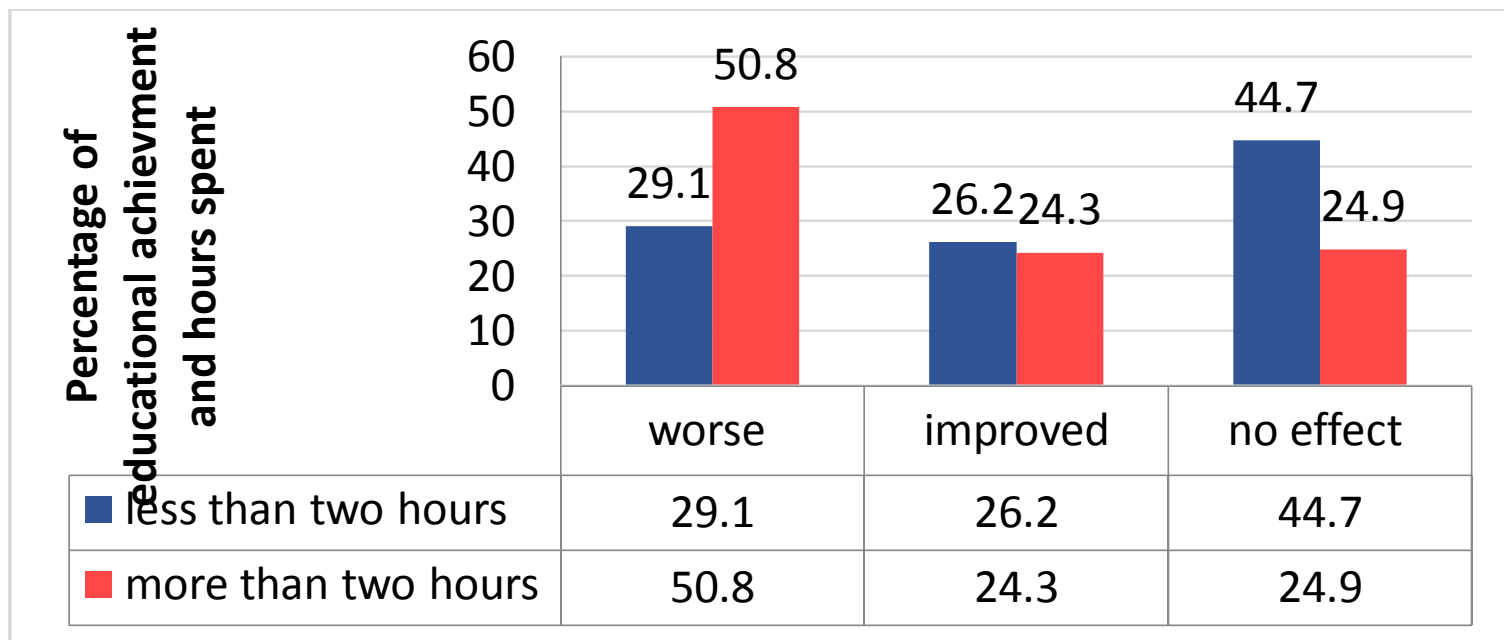

Figure 9:- Association between educational achievement and screen time use After assessing the relation between educational achievement and screen time use, 50.8\% of the children who their educational performance got worse spend equal or more than Two hours on the electronic devices(Figure 9).

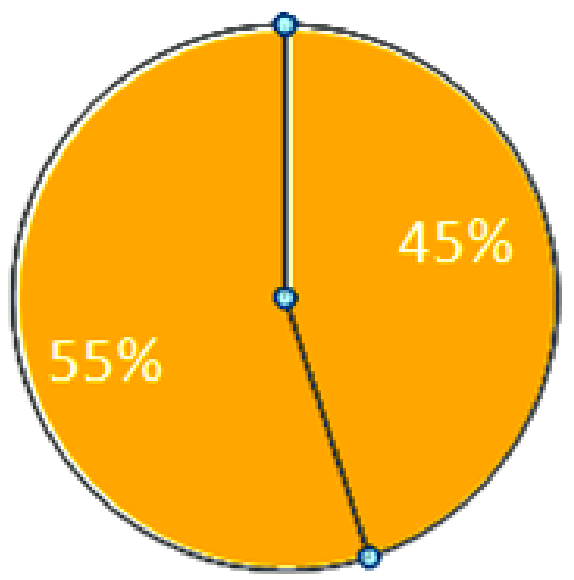

Figure 10:- Mothers observations on social changes on their children $55 \%$ of the mothers did not observe social changes in their children (Figure 10). 
Table 5:- The relationship between parenting style and child electronic use

\begin{tabular}{|c|c|c|c|c|}
\hline Electronic Use & Categories & Authoritative $\mathrm{M} \pm \mathrm{SD}$ & $\begin{array}{c}\text { Authoritarian } \\
\mathbf{M} \pm \text { SD }\end{array}$ & $\begin{array}{c}\text { Permissive } \\
\text { M } \pm \text { SD }\end{array}$ \\
\hline \multicolumn{5}{|l|}{ Day/week } \\
\hline & Every day & $31.95 \pm 8.98$ & $18.17 \pm 5.71$ & $16.90 \pm 3.94$ \\
\hline & 4-6 D / W & $33.95 \pm 7.02$ & $15.50 \pm 4.68$ & $15.95 \pm 4.02$ \\
\hline & 3-2 D / W & $31.72 \pm 8.30$ & $18.83 \pm 5.02$ & $16.03 \pm 3.86$ \\
\hline & $1 \mathrm{D} / \mathrm{W}$ & $34.09 \pm 8.72$ & $16.91 \pm 6.78$ & $14.63 \pm 3.98$ \\
\hline $\boldsymbol{F}$ & & .702 & 2.354 & 2.538 \\
\hline P value & & .552 & .073 & $.057 *$ \\
\hline \multicolumn{5}{|c|}{ Setting Restrictions In Electronics Use } \\
\hline & Never & $33.11 \pm 9.66$ & $16.70 \pm 5.87$ & $16.19 \pm 3.94$ \\
\hline & Rarely & $31.64 \pm 7.60$ & $18.0 \pm 4.20$ & $18.44 \pm 3.58$ \\
\hline & Sometimes & $32.06 \pm 7.91$ & $17.53 \pm 5.11$ & $16.80 \pm 3.83$ \\
\hline & Always & $32.27 \pm 9.49$ & $18.67 \pm 6.25$ & $15.84 \pm 4.17$ \\
\hline Kruskal & & .095 & 1.119 & 2.652 \\
\hline $\mathrm{P}$ value & & .963 & .342 & $.049 *$ \\
\hline
\end{tabular}

* Significant difference at $\mathrm{p} \leq .05$

According to the table 5 , the findings of restrictions imposed by parents for children's electronics use, the permissive parenting style has a significant effect on restrictions in electronic use; Kruskal $(257)=2.65, p=0.04$, and significant effect on the times the child use electronics per week; $f(257)=2.53, p=.057$.

Table 6:- The relationship between family Characteristics and parenting style

\begin{tabular}{|c|c|c|c|c|}
\hline $\begin{array}{c}\text { Family } \\
\text { characteristics }\end{array}$ & Categories & Authoritative & Authoritarian & Permissive \\
\hline \multicolumn{5}{|l|}{ Mother } \\
\hline \multicolumn{5}{|l|}{ Age } \\
\hline \multirow[t]{3}{*}{ (years) } & $25-35$ & $32.20 \pm 8.44$ & $18.47 \pm 5.82$ & $16.62 \pm 3.98$ \\
\hline & $36-45$ & $31.95 \pm 9.10$ & $17.60 \pm 5.65$ & $16.35 \pm 4.14$ \\
\hline & More than 46 & $32.42 \pm 8.59$ & $17.82 \pm 4.92$ & $16.43 \pm 3.84$ \\
\hline$F$ & & .034 & .903 & .139 \\
\hline p value & & .966 & .407 & .871 \\
\hline \multicolumn{5}{|l|}{ Nationality } \\
\hline & Saudi & $31.38 \pm 8.70$ & $18.074 \pm 5.68$ & $16.46 \pm 4.053$ \\
\hline & Non-Saudi & $36.61 \pm 6.27$ & $16.918 \pm 5.57$ & $16.342 \pm 3.981$ \\
\hline$T$ & & -4.198 & 1.160 & .173 \\
\hline p value & & $.016^{*}$ & .339 & .708 \\
\hline \multicolumn{5}{|l|}{ Edu level } \\
\hline & High School & $31.52 \pm 9.84$ & $17.97 \pm 6.02$ & $17.44 \pm 3.87$ \\
\hline & Bachelor & $31.31 \pm 8.29$ & $18.05 \pm 5.53$ & $16.51 \pm 3.97$ \\
\hline & Master & $31.89 \pm 8.48$ & $19.47 \pm 6.16$ & $17.27 \pm 4.33$ \\
\hline & Phd & $34.60 \pm 8.57$ & $16.74 \pm 5.16$ & $15.16 \pm 3.66$ \\
\hline$F$ & & 1.762 & 1.773 & 3.238 \\
\hline P value & & .155 & .153 & $.023 *$ \\
\hline \multicolumn{5}{|l|}{ Work Nature } \\
\hline & Educational & $32.95 \pm 7.37$ & $18.55 \pm 5.87$ & $16.87 \pm 4.40$ \\
\hline & Administrative & $31.82 \pm 8.61$ & $17.86 \pm 5.62$ & $16.51 \pm 3.90$ \\
\hline & Both & $32.10 \pm 11.44$ & $17.46 \pm 5.42$ & $15.35 \pm 3.58$ \\
\hline$F$ & & .353 & .484 & 1.530 \\
\hline P value & & .703 & .617 & .219 \\
\hline \multicolumn{5}{|l|}{ Marital Status } \\
\hline & Married & $32.25 \pm 8.74$ & $18.11 \pm 5.61$ & $16.52 \pm 3.91$ \\
\hline & Divorced & $32.58 \pm 6.88$ & $15.33 \pm 6.32$ & $14.25 \pm 4.71$ \\
\hline
\end{tabular}




\begin{tabular}{|c|c|c|c|c|}
\hline & Widowed & $28.80 \pm 8.92$ & $17.66 \pm 5.85$ & $18.16 \pm 4.91$ \\
\hline $\boldsymbol{F}$ & & .401 & 1.389 & 2.437 \\
\hline P value & & .670 & .251 & .089 \\
\hline Children No. & & & & $16.26 \pm 3.97$ \\
\hline & $\mathbf{1 - 2}$ & $32.36 \pm 8.45$ & $18.05 \pm 5.84$ & $16.56 \pm 4.21$ \\
\hline & $\mathbf{3 - 4}$ & $31.56 \pm 9.05$ & $17.83 \pm 5.67$ & $16.85 \pm 3.69$ \\
\hline $\boldsymbol{F}$ & More than 5 & $33.03 \pm 8.53$ & $18.10 \pm 5.18$ & .371 \\
\hline P value & & .405 & .053 & .690 \\
\hline
\end{tabular}

* Significant difference at $\mathrm{p} \leq .05$ Nationality is assessed byMann Whitney

As illustrated in table 6, there was a significant association between permissive parenting style and educational level; $f(257)=3.23, p=0.02$. Therewas no significant association betweenauthoritarian parenting style and mothers characteristics, significant association between authoritative parenting style and nationality; $t(232)=-4.19, p=.01$.

Table 7:- Correlation between Different Parenting Style Subscales and Screen Time Use of their Children on Electronic Use

\begin{tabular}{|l|c|c|c|c|}
\hline & 1 & 2 & 3 & 4 \\
\hline 1. Screen time use & 1 & & & \\
\hline 2. Authoritative & -.009 & 1 & & \\
\hline 3. Authoritarian & -.020 & $-.356^{* *}$ & 1 & \\
\hline 4. Permissive & .090 & $-272^{* *}$ & $.488^{* *}$ & 1 \\
\hline
\end{tabular}

**Correlation is significant at the 0.01 level (2-tailed).

As shown in the table 7, the authoritative and authoritarian parenting style were negatively correlated to the screen time use of their children $\left(r_{s}=-.009, p=.89\right),\left(r_{s}=-.020, p=.75\right)$. Only the permissive parenting style is directly correlated to the screen time use $\left(r_{s}=.090, p=.15\right)$

\section{Discussion:-}

The percentage of different maternal parenting style among female employees at PNU was identified and according to the findings, the majority of the participants were authoritative mothers and the minority were permissive ones. Our findings are consistent with a study conducted in Europe, where the majority were similarly authoritative, and the minority were authoritarian and permissive. It has been found that there is no significant correlation between different parenting style and screen time they allow for their children. In the authoritarian and the authoritative, the result showed a negatively correlated relationship with screen time. In contrast, permissive parenting style has a direct relationship, therefore, children with parents who are permissive have the ability to spend more hours on screen.Similarly, the permissive parenting style has a significant effect on the number of times the child use electronics per week, because of the low restrictions applied, then the other children with authoritarian and authoritative parents who apply high restrictions on screen time use. The association between permissive parenting style and television viewing among children, proportionate with the results of this study and showed that children with permissive parents were twice as likely to spend more hours watching TV compared with children from highrestriction families. ${ }^{(19)} \mathrm{A}$ body of researches has concluded similar results which stated that the permissive parenting style is associated with high rates of physical activities because of their support and low restrictions applied, unlike the authoritative parenting style which was not associated PA. Authoritative parent's children scored lower levels of physical activities because of their high demands, strict discipline and high restriction. Complementary to the previous findings, the authoritative parents were more likely to monitor their children's eating habits while the authoritarian parents apply restrictions on their children's eating habits unlike the permissive parents who were less likely to use restriction on their children in general. ${ }^{(20)}$ The physical and behavioral wellbeing, and social ability of children were affected after the time spent on electronic devices as reported by the mothers and were more likely to be negatively influenced. Our surveys documented a statistically significant relationship between the screen time and perceived negative health effects on $63 \%$ of children who spent equal or more than two hours on electronic devices. The children's physical health was assessed and the results showed that the majority of children were suffering mildly from eye exhaustion, concentration loss, tiredness and headache, and sleeping problems, in addition to behavioral changes where children adopted violent and anger behaviors alone with social changes where children became unsocial. The educational performance was another important domain of the children's life that has been 
influenced by the screen time use. A high percentage of mothers who reported that their children spent more than two hours on electronic devices faced a deterioration in their children's educational performance and in support for this finding, another study has suggested that heavy users of video games suffered from a detrimental effect on their educational performance, counter to the moderate users of video games and internet who had positive educational performance. Indeed, similar to our findings, a recent study conducted in Iran provided a robust evidence that more than $15 \%$ of children spend more than 10 hours per week playing video games and concluded that the longer the hours spent on playing games - the more negative affects detected such as aggressive behaviors. ${ }^{(21,22)}$ Therefore, parents must apply restrictions to limit the effect of perceived negative hazards of electronics devices, and according to our study, an association between permissive parenting style and educational level was noted and a study conducted in Saudi Arabia found that there is a relationship between the parent's educational level and knowledge about internet use and risk of websites on children and unexpectedly suggested that the educational level of parents had no significant effect on how they apply restrictions on their children's internet use along counter to our study. (23)

Age of mothers played an important role in determining the application of restrictions upon children's screen time use and it was found that younger mothers are more likely to force restrictions upon their children compared to older mothers who were less likely to apply restrictions.

\section{Strengths and Limitation of the study:-}

To our knowledge, it is the first study in Saudi Arabia that assessed the effect of different parenting styles on the hours spent by children on electronic devices. In addition, we used a tool proved to be of high validity and reliability. The study faced several other limitations such as the short time of the study was an important obstacle that has limited the research, especially the data collection phase in addition to the availability for employees that also has affected the data collection because most of them were either on vacation or on giving lectures. In addition, no enough body of researches conducted in Saudi Arabia on the parenting style and its effect on the children's electronic use, which has made the comparative analysis difficult.

\section{Conclusion:-}

Our study presented findings that showed there is no significance between parenting style and level of control on children screen time use. However, children's physical, behavioral wellbeing, social and educational performance were affected when children spent more than two hours on electronics. Hence, parents must apply more restrictions and limitation to bind their children from the perceived negative hazards of electronic.

\section{Recommendations and Implications of the research:-}

The results we concluded in our study may participate in the implication of extensive policies therefore the following are recommended:

1- Additional studies in this domain are recommended in order to understand the effect of maternal parenting style on the children's electronic use on a bigger sample using different type of studies to generalize the results.

2- Further interventions are needed to improve the awareness of parents on the effect of electronic devices on children and how to deal with them and provide alternative activities for children to lessen the time spent on electronics.

3- Implement intervention programs in schools that targets children and aims to teach them about the consequences of excessive electronics use and encourage different physical activities.

Conflict of interest:- The author declared no conflict of interest.

\section{References:-}

1. Law, C.S. The impact of changing parenting styles on the advancement of pediatric oral health. CDA Journal, 2007;3, 192-197

2. Darling N, Steinberg L: Parenting style as context: An integrative model. Psychological Bulletin. 1993, 113: 487-496. 10.1037/0033-2909.113.3.487.

3. Teresia M. Physical Activity and Screen-Media-Related Parenting Practices Have Different Associations with Children's Objectively Measured Physical Activity. Childhood Obesity. September 12, 2013.9(5).451.

4. Hoda N, Ahmad A, Melibari A. Analysis of Demographic Factors, Internet Usage and Online Shopping for Social Media Users in Saudi Arabia. SSRN Electronic Journal. 
5. Hart CRobinson. (2001). The parenting styles and dimensions questionnaire (PSQD). In B. F. Perlmutter,J. Touliatos\& G. W. Holden (Eds.),Handbook of family measurement techniques: Vol. 3.Instruments \& Index (pp.319 321).Thousand Oaks: Sage.

6. Joseph M, John J. Impact of parenting styles on child development.2008. Global Academic Society Journal: Social Science Insight. 1(5). 17.

7. Veldhuis L, van Grieken A, Renders C, HiraSing R, Raat H. Parenting Style, the Home Environment, and Screen Time of 5-Year-Old Children; The 'Be Active, Eat Right' Study. PLoS ONE. 2014;9(2):e88486.

8. Sălceanu C. The Influence of Computer Games on Children's Development. Exploratory Study on the Attitudes of Parents. Procedia - Social and Behavioral Sciences. 2014;149:837-841.

9. Gunter B. The effects of video games on children. Sheffield, England: Sheffield Academic Press; 1998.

10. Arredondo E, Elder J, Ayala G, Campbell N. Is parenting style related to children's healthy eating and physical activity in Latino families?. Health Education Research. 2006;21(6):862-871.

11. Sarita A. Yardi. Social Media At The Boundaries: Supporting Parents In Managing Youth's Social Media Use. 2012;.

12. Joseph M, John J. Impact of parenting styles on child development.2008. Global Academic Society Journal: Social Science Insight. 1(5). 17.

13. O'Keeffe GClarke-Pearson K. The Impact of Social Media on Children, Adolescents, and families. Pediatrics. 2011;127(4):800-804.

14. Dean AG, Sullivan KM, Soe MM. OpenEpi: Open Source Epidemologic Statistics for Public Health, Version. www.OpenEpi.com, updated 2013/04/06, accessed 2016/5/10

15. Allahverdipour H, Bazargan M, Farhadinasab A, Moeini B. Correlates of video games playing among adolescents in an Islamic country. BMC Public Health. 2010;10:286.

16. American Academy of Pediatrics. (2013). Policy statement. Children, adolescents, and the media. Pediatrics, $132,958-961$

17. Nagwa A. Zein El Dein. Harmful Effect of Commonly Used Electronic Devices on Adolescence and its Safeguard at Shebin El-Kom IOSR Journal of Nursing and Health Science (IOSR-JNHS). e-ISSN: 23201959.p- ISSN: 2320-1940 Volume 2, Issue 1 (Sep. - Oct. 2013), PP 32-46

18. IBM Crop. Released 2016. IBM SPSS Statistics For Windows, Virsion 20.0 Armonk, NY: BMI Crop.

19. Jago R, Davison K, Thompson J, Page A, Brockman R, Fox K. Parental Sedentary Restriction, Maternal Parenting Style, and Television Viewing Among 10- to 11-Year-Olds. PEDIATRICS. 2011;

20. Hennessy E, Hughes S, Goldberg J, Hyatt R, Economos C. Parent-child interactions and objectively measured child physical activity: a cross-sectional study. International Journal of Behavioral Nutrition and Physical Activity. 2010;7(1):71.

21. Allahverdipour H, Bazargan M, Farhadinasab A, Moeini B. Correlates of video games playing among adolescents in an Islamic country. BMC Public Health. 2010;10(1).

22. Willoughby T, Willoughby T: A short-term longitudinal study of Internet and computer game use by adolescent boys and girls: prevalence, frequency of use, and psychosocial predictors. Developmental Psychology 2008, 44:195-204.

23. Almogbel, A., Begg, M. and Wilford, S.H. Analysis of the relationship between Saudi Arabia parents' education and economic level parental control of internet usage. The Macrotheme Review 2015, 4 (2), pp. 14215 